\title{
VERIFIKASI LOGAM TIMBAL PADA URIN DENGAN VARIASI ZAT PENGOKSIDASI DAN METODE DESTRUKSI BASAH PADA PEROKOK AKTIF
}

\author{
Dyna Putri Mayaserli ${ }^{1 *}$, Dewi Yudiana Shinta ${ }^{1}$ \\ ${ }^{1}$ D-III Teknologi Laboratorium Medik, STIKes Perintis Padang \\ Jalan Adinegoro KM 17 Simpang Kalumpang Padang, Sumatera Barat \\ *Email:dyna2205@yahoo.com
}

\begin{abstract}
Lead $(\mathrm{Pb})$ is heavy metal which is naturally found in the earth's crust or originates from human activities, for example from combustion gas emissions in motorized vehicle engines. Republic of Indonesia Ministry of Health Number 1406 / MENKES / SKI / IX / 2002 concerning the examination of lead levels in human biomarker specimens human measurements of lead levels in the human body can be carried out by blood, urine and hair specimens. The purpose of this study is to determine the levels of lead metal in the urine of active smokers. The results of research on lead levels obtained on accuracy parameters, namely the accuracy test results for the method of wet destruction using $\mathrm{HNO} 3$ has an average recovery of $71.8 \%$ while using $\mathrm{HNO}_{3}$ added $\mathrm{H}_{2} \mathrm{SO}_{4}$ has an average recovery of $46.48 \%$, precision test results are obtained \% RSD method of destruction on $\mathrm{HNO}_{3}$ was $28.80 \%$. If on $\mathrm{HNO}_{3}$ added $50.58 \% \mathrm{H}_{2} \mathrm{SO}_{4}$, linearity test (r) 0.999 , LoD value on $\mathrm{HNO}_{3}$ 0.76 and on $\mathrm{LoD} \mathrm{HNO}_{3} \mathrm{H}_{2} \mathrm{SO}_{4}$ added. Based on the results of the study of verification of lead metal using wet digestion in the urine of active smokers not in the range of acceptability conditions it indicates that the method cannot be valid for use in the examination of lead in urine by the method of wet destruction in the active smookers.
\end{abstract}

Keywords: Plumbum, Urine, Active Smookers, AAS

\section{PENDAHULUAN}

Timbal merupakan logam berat yang terdapat di dalam kerak bumi atau berasal dari kegiatan manusia, misalnya emisi gas sisa pembakaran dalam mesin kendaraan bermotor. Logam berat dalam tubuh manusia biasanya terdapat pada beberapa organ tubuh seperti ginjal, hati, kuku, jaringan adiposa, dan rambut (Mayaserli, Renowati, \& Biomed, 2018) Analisa kandungan logam berat pada darah ataupun urin pada umumnya tidak bertahan lama dan dapat segera dikeluarkan melalui siklus metabolisme tubuh (Achadi, 2008), sedangkan analisis logam berat melalui rambut dapat diketahui secara akurat (Amirudin R, 2009). Hal ini disebabkan logam berat lebih bertahan lama dirambut, dimana jumlah logam dalam rambut berkolerasi dengan jumlah logam yang diabsorbsi (Lawrence, 2003)

Sumber $\mathrm{Pb}$ dapat berasal dari alam dan sebagai akibat antropogenik (Sitepoe, 2000). Secara alamiah $\mathrm{Pb}$ di lingkungan berasal dari pelapukan geologis dan letusan gunung berapi. Aktivitas antropogenik masuknya $\mathrm{Pb}$ ke lingkungan berasal dari berbagai aktivitas antara lain pertambangan, peleburan, dan sebagai hasil samping dari industri accu, kabel, pigmen, produksi baja serta dari hasil pembakaran bahan bakar bensin yang mengandung zat aditif (Tetra Ethyl Lead) dan (Tetra Methyl Lead) (Palar, 1994)

Diperkirakan dari kegiatan pertambangan dan peleburan jumlah $\mathrm{Pb}$ yang diemisikan ke lingkungan sekitar 126.000 ton/tahun, dan dari 
kegiatan lainnya sekitar 3 juta ton/tahun (Manahan, 1992).

Zat pengoksidasi seperti $\mathrm{HNO}_{3}, \mathrm{HCIO}_{4}$, $\mathrm{H}_{2} \mathrm{SO}_{4}, \quad \mathrm{H}_{2} \mathrm{O}_{2}$, dan $\mathrm{HCl}$ diyakini dapat mengoksidasi timbul zat pengoksidasi asam nitrat $\left(\mathrm{HNO}_{3}\right)$ dan campuran $\mathrm{HNO}_{3}$ dengan $\mathrm{HCLO}_{4}$ merupakan pengoksidasi utama yang dapat memberikan hasil destruksi terbaik dibandingkan pengoksidasi lainnya (Harmita, 2006)

Keputusan Menteri Kesehatan Republik Indonesia Nomor1406/MENKES/ SKI/IX/2002 tentang standar pemeriksaan kadar timah hitam pada spesimen biomarker manusia, pengukuran kadar timbal pada tubuh manusia dapat dilakukan melalui spesimen darah, urine dan rambut. Nilai ambang batas kadar $\mathrm{Pb}$ dalam specimen urine adalah $150 \mathrm{ug} / \mathrm{ml}$ creatinine (Bjork, J., Albin, M., Mauritzson, N., Stromberg, U., Johansson, B., and Hagmar, 2000)

Perokok aktif adalah orang yang merokok dan langsung menghisap rokok yang bisa mengakibatkan bahaya bagi kesehatan diri sendiri maupun lingkungan sekitar (John Adamson, 1990). Berdasarkan latar belakang di atas maka peneliti ingin melakukan penelitian tentang analisa kadar logam timbal $\mathrm{Pb}$ pada darah dengan variasi zat pengoksidasi dan metode destruksi basah pada perokok aktif.

\section{METODE PENELITIAN}

Penelitian ini bersifat Eksperimen. Desain penelitian adalah analisa pendekatan crossectional dengan metode analisa laboratorium dan Uji Validasi Spektrofotometer Serapan Atom (AAS). Peralatan yang digunakan adalah: Spektrofotometer Serapan Atom, Labu Ukur $25 \mathrm{ml}$, beaker gelas, Pipet Gondok $5 \mathrm{ml}$ dan corong. Bahan yang digunakan adalah: Urin, Aquades, $\mathrm{HNO}_{3}$, $\mathrm{H}_{2} \mathrm{SO}_{4}$, Larutan standar $\mathrm{Pb}$.

\section{Pengukuran Larutan dengan Alat AAS}

Panjang gelombang $283 \mathrm{~nm}$, panjang logam yang diperoleh pada kurva absorpsi Penentuan panjang gelombang maksimum dilakukan terlebih dahulu dengan memasang lampu katoda berongga $\mathrm{Pb}$ lalu dihidupkan tombol power pada alat AAS, kemudian diatur lampu sesuai dengan logam yang diinginkan melalui software, diatur maksimum ini digunakan untuk pengukuran konsentrasi logam $\mathrm{Pb}$ dalam sampel.

\section{Pemeriksaan sampel dengan larutan $\mathrm{HNO}_{3}$}

Sampel urin diambil sebanyak $22,5 \mathrm{ml}$, masukkan ke dalam beaker glass, tambahkan Larutan $\mathrm{Pb}$ Sebanyak 2,5 ml dan tambahkan larutan $\mathrm{HNO}_{3}$ sebanyak $5 \mathrm{ml}$. Kemudian dipanaskan dalam lemari asam sampai asam merah hilang. Sampel diangkat kemudian didinginkan, setelah dingin, pindahkan sampel ke dalam labu ukur $25 \mathrm{ml}$ dengan menggunakan corong, tambahkan aquades hingga tanda batas labu ukur $25 \mathrm{ml}$, selanjutnya sampel diukur dengan alat Spektrofotometer Serapan Atom (AAS).

\section{Pemeriksaan sampel dengan larutan $\mathrm{HNO}_{3}+$ $\mathrm{H}_{2} \mathrm{SO}_{4}$}

Sampel urin diambil sebanyak $22,5 \mathrm{ml}$, masukkan ke dalam beaker glass, tambahkan Larutan $\mathrm{Pb}$ Sebanyak 2,5 ml, tambahkan larutan $\mathrm{HNO}_{3}$ sebanyak $5 \mathrm{ml}$, dan tambahkan Larutan $\mathrm{H}_{2} \mathrm{SO}_{4} 5 \mathrm{ml}$, kemudian dipanaskan dalam lemari asam sampai asam merah hilang, sampel diangkat kemudian didinginkan, setelah dingin, pindahkan sampel ke dalam labu ukur $25 \mathrm{ml}$ dengan menggunakan corong, tambahkan aquades hingga tanda batas labu ukur $25 \mathrm{ml}$, selanjutnya sampel diukur dengan alat Spektrofotometer Serapan Atom (AAS).

Validasi Pengukuran $\mathrm{Pb}$ pada urin metode AAS

\section{a. Uji akurasi (ketepatan)}

Uji ini dilakukan dengan cara menambahkan larutan baku pembanding $(\mathrm{Pb} 10$ ppm) ke dalam sampel yang akan diperiksa sebelum didestruksi dengan sampel di duplo. Kemudian dilakukan uji blanko (tanpa penambahan larutan baku standar). Masingmasing sampel kemudian didestruksi dengan metode destruksi basah menggunakan $\mathrm{HNO}_{3}$, $\mathrm{H}_{2} \mathrm{SO}_{4}$ dan diukur menggunakan AAS pada panjang gelombang 283,3 nm (Al Anshori, 2005)

b. Uji presisi pengukuran $\mathrm{Pb}$ pada urin metode spektrofotometer serapan atom (AAS) 
Metode uji presisi dilakukan secara repibilitas atau keterulangan dilakukan dalam kondisi yang sama dalam interval waktu yang singkat, yaitu dengan mengukur larutan sampel metode destruksi basah menggunakan $\mathrm{HNO}_{3}$, $\mathrm{H}_{2} \mathrm{SO}_{4}$ dan dengan sampel di duplo pada hari yang sama, kemudian data hasil absobrs dihitung simpangan bakunya.

c. Uji linieritas pengukuran $\mathrm{Pb}$ pada urin Metode Spektrofotometer Serapan atom (SSA)

Metode uji presisi dilakukan secara repitabilitas atau keterulangan dilakukan dalam kondisi yang sama dalam interval waktu yang singkat, yaitu dengan mengukur larutan sampel metode detsruksi basah menggunakan $\mathrm{HNO}_{3}$ dan $\mathrm{H}_{2} \mathrm{SO}_{4}$ dengan melakukannya duplo pada hari yang sama, hasil absorban di hitung simpangan bakunya.

d. Uji limit deteksi (LoD) dan limit kuantitas (LoQ) pengukuran $\mathrm{Pb}$ pada urin metode spektrootometer serapan atom (AAS)

Uji ini dilakukan dengan mengukur kosentrasi standar yang paling rendah yang dapat terdeteksi absorbansinya.

$$
\mathrm{LoD}=3 \mathrm{X} \mathrm{SD}
$$

Sedangkan LoQ dapat dihitung dengan rumus: LoQ $=10 \times$ SD

Pengolahan Data pada penelitian ini menggunakan Uji Validasi, presisi dan akurasi.

\section{HASIL DAN PEMBAHASAN}

Sampel penelitian yang dipergunakan adalah urin sebanyak 10 sampel pada perokok aktif. Semua responden berjenis kelamin lakilaki yang diperiksa kadar timbal dalam urin.

Berdasarkan Tabel 1 diketahui bahwa distribusi responden berdasarkan umur sebagian besar berada pada kelompok umur 20-25 tahun yaitu berjumlah 4 orang dengan persentase $40 \%$. Sedangkan berdasarkan jumlah rokok sebagian besar mengkonsumsi 10-20 batang rokok perhari yaitu berjumlah 5 orang dengan persentase 50\% dapat dilihat pada Tabel 2.

Tabel 1. Distribusi Koresponden Berdasarkan Umur

\begin{tabular}{ccc}
\hline Umur & Jumlah & Persentase \\
\hline $20-25$ & 4 & $40 \%$ \\
$26-30$ & 3 & $30 \%$ \\
$31-35$ & 2 & $20 \%$ \\
$36-40$ & 1 & $10 \%$ \\
$41-45$ & 0 & $0 \%$ \\
Total & 10 & $100 \%$ \\
\hline
\end{tabular}

Tabel 2. Distribusi Responden Berdasarkan Jumlah Rokok

\begin{tabular}{ccc}
\hline Konsumsi rokok/hari (batang) & Jumlah & Persentase \\
\hline $0-5$ & 2 & $20 \%$ \\
$5-10$ & 3 & $30 \%$ \\
$10-20$ & 5 & $50 \%$ \\
Total & 10 & $100 \%$ \\
\hline
\end{tabular}

Tabel 3. Distribusi Responden Berdasarkan Lama Konsumsi Rokok

\begin{tabular}{ccc}
\hline Lama Merokok (tahun) & Jumlah & Persentase \\
\hline $3-5$ & 3 & $30 \%$ \\
$5-10$ & 4 & $40 \%$ \\
$10-20$ & 2 & $20 \%$ \\
$20-30$ & 1 & $10 \%$ \\
Total & 10 & $100 \%$ \\
\hline
\end{tabular}


Mayaserli, D.P., Shinta, D.Y. 2019. Verifikasi Logam Timbal pada Urin dengan Variasi Zat Pengoksidasi dan Metode Destruksi Basah pada Perokok Aktif. Sainstek : Jurnal Sains dan Teknologi. 11 (1) : 01 - 07

Tabel 4. Distribusi Responden Berdasarkan Kandungan Timbal $(\mathrm{Pb})$ dalam Urin

\begin{tabular}{cccccc}
\hline No & Sampel & Umur & Lama Merokok (th) & Kadar $\mathrm{Pb} \mathrm{HNO}_{3}(\mathrm{mg} / \mathrm{dl})$ & Kadar $\mathrm{Pb} \mathrm{H}_{2} \mathrm{SO} \mathrm{HNO}_{3}(\mathrm{mg} / \mathrm{dl})$ \\
\hline 1 & RG & 37 & $20-30$ th & 0,384 & 0,636 \\
2 & DR & 24 & $3-5$ th & 0,028 & 0,027 \\
3 & DN & 35 & $10-20$ th & 0,274 & 0,305 \\
4 & RD & 35 & $10-20$ th & 0,291 & 0,249 \\
5 & AL & 27 & $5-10$ th & 0,006 & 0.856 \\
6 & AG & 24 & $5-10$ th & 0,049 & 0,244 \\
7 & FZ & 23 & $3-5$ th & 0,002 & 0,794 \\
8 & MD & 25 & $3-5$ th & 0,120 & 0.356 \\
9 & AD & 29 & $5-10$ th & 0,204 & 0,07 \\
10 & FA & 28 & $5-10$ th & 0,020 & 0,275 \\
\hline
\end{tabular}

Berdasarkan Tabel 3 diketahui bahwa distribusi responden berdasarkan lama konsumsi rokok sebagian besar telah lama merokok selama 5 - 10 tahun, yaitu berjumlah 4 orang dengan persentase $40 \%$.

Berdasarkan Table 4 diketahui bahwa responden berdasarkan kandungan timbal $(\mathrm{Pb})$ dalam urin pada larutan $\mathrm{HNO}_{3}$ yang tertinggi terdapat pada sampel no 1 yaitu $0,384 \mathrm{mg} / \mathrm{dl}$ sedangkan kadar $\mathrm{Pb}$ dalam pada larutan $\mathrm{HNO}_{3}$ ditambahkan $\mathrm{H}_{2} \mathrm{SO}_{4}$ kadar $\mathrm{Pb}$ tertinggi yaitu 0,856 . Kemungkinan tingginya hasil uji yang didapat Karena larutan $\mathrm{HNO}_{3}$ sebagai agen pengoksidasi utama, dan $\mathrm{HNO}_{3}$ pelarut logam yang baik, $\mathrm{Pb}$ teroksidasi oleh $\mathrm{HNO}_{3}$ sehingga menjadi larut. Sedangkan $\mathrm{H}_{2} \mathrm{SO}_{4}$ berfungsi sebagai katalis untuk mempercepat terputusnya reaksi logam timbal $\mathrm{Pb}$ dari senyawa yang ada dalam sampel. $\mathrm{H}_{2} \mathrm{SO}_{4}$ juga mempengaruhi lingkungan sehingga katalis ini tidak ikut bereaksi.

Campuran asam sulfat pekat dan asam nitrat pekat banyak digunakan untuk mempercepat proses destruksi. Kedua asam ini merupakan oksidator yang kuat. Dengan penambahan oksidator ini akan menurunkan suhu destruksi sampel yaitu pada suhu $35{ }^{\circ} \mathrm{C}$, dengan demikian komponen yang dapat menguap atau terdekomposisi pada suhu tinggi dapat dipertahankan dalam sampel.

\section{Uji Akurasi Analisa Timbal dalam Urin Pada Perokok Aktif.}

Pada Destruksi Metode Basah dengan menggunakan $\mathrm{HNO}_{3}$ mempunyai rata-rata recovery $96,24 \%$. Dengan demikian metode destruksi sudah baik karena berada pada nilai persentase recovery yang disarankan yaitu $100 \% \pm 15$ dengan nilai yang lebih mendekati $100 \%$. Rentang tersebut dianggap baik karena menunjukkan bahwa metode tersebut mempunyai ketepatan yang tinggi dengan nilai sebenarnya. Dengan kata lain pada proses destruksi tidak adanya $\mathrm{Pb}$ yang hilang (Handoy S.Y., 2008)

Berdasarkan Tabel 5 diketahui bahwa responden dengan nilai presentase recovery dan koefisien varian kandungan timbal pada urin perokok menggunakan $\mathrm{HNO}_{3}$ secara berturutturut $71,8 \%$ dan $28,80 \%$. Kandungan matriks atau ion-ion lain dapat mengganggu proses analisis logam berat dengan spektroskopi serapan atom. Hal ini mengakibatkan akurasi hasil analisis menjadi rendah. Oleh karena itu sebelum analisis dilakukan destruksi perlu dilakukan pemisahan kandungan ion lain, dengan seminimal mungkin. Metode perlakukan awal yang digunakan adalah metode destruksi yaitu dengan memutuskan ikatan unsur logam dengan komponen lain (Khopkar, 2008) 
Mayaserli, D.P., Shinta, D.Y. 2019. Verifikasi Logam Timbal pada Urin dengan Variasi Zat Pengoksidasi dan Metode Destruksi Basah pada Perokok Aktif. Sainstek : Jurnal Sains dan Teknologi. 11 (1) : 01 - 07

Tabel 5. Nilai Persentase Recovery Analisa Timbal dalam Urin pada Perokok Aktif Memakai Larutan $\mathrm{HNO}_{3}$

\begin{tabular}{cccccccccc}
\hline $\begin{array}{c}\text { No. } \\
\text { Sampel }\end{array}$ & A & B & $\begin{array}{c}\text { Konsentrasi } \\
\text { Spike (Mg/l) }\end{array}$ & A-B & Jml & Mean & SD & $\%$ R & \%CV \\
\hline L.0783 & 1,133 & 0,384 & 1 & 0,749 & & & & & \\
L.0784 & 0,477 & 0,028 & 1 & 0,4486 & & & & & \\
L.0785 & 0,513 & 0,274 & 1 & 0,238 & & & & & \\
L.0786 & 1,249 & 0,291 & 1 & 0,958 & & & & & \\
L.1120 & 0,928 & 0,006 & 1 & 0,922 & & & & \\
L.1121 & 0,833 & 0,49 & 1 & 0,343 & 8,18 & 0,8816 & 0,2539 & 71,8 & 28,80 \\
L.1122 & 0,784 & 0,002 & 1 & 0,782 & & & & & \\
L.1123 & 0,814 & 0,12 & 1 & 0,694 & & & & & \\
L.1124 & 1,121 & 0,02 & 1 & 1,101 & & & & & \\
L.1125 & 0,964 & 0,02 & 1 & 0,944 & & & & & \\
\hline
\end{tabular}

Tabel 6. Nilai Persentase Analisa Recovery Analisa Timbal Urin Perokok Aktif Menggunakan $\mathrm{HNO}_{3}$ Ditambahkan $\mathrm{H}_{2} \mathrm{SO}_{4}$

\begin{tabular}{|c|c|c|c|c|c|c|c|c|c|}
\hline No. & & & Konsentrasi & & & & & & \\
\hline Sampel & A & B & Spike $(\mathrm{Mg} / \mathrm{l})$ & A-B & $\mathrm{Jml}$ & Mean & SD & $\% \mathrm{R}$ & $\% \mathrm{CV}$ \\
\hline L.0783 & 0,759 & 0,636 & 1 & 0,123 & & & & & \\
\hline L.0784 & 0,347 & 0,027 & 1 & 0,32 & & & & & \\
\hline L.0785 & 0,274 & 0,305 & 1 & $-0,031$ & & & & & \\
\hline L.0786 & 0,224 & 0,249 & 1 & 0,224 & & & & & \\
\hline L.1120 & 0,771 & 0,856 & 1 & 0,771 & & & & & \\
\hline L. 1121 & 0,534 & 0,244 & 1 & 0,22 & 4,476 & 0,4476 & 0,2264 & 46,48 & 50,58 \\
\hline L. 1122 & 0,715 & 0,794 & 1 & 0,715 & & & & & \\
\hline L. 1123 & 0,321 & 0,356 & 1 & 0,321 & & & & & \\
\hline L. 1124 & 0,201 & 0,07 & 1 & 0,063 & & & & & \\
\hline L. 1125 & 0,33 & 2,75 & 1 & 0,248 & & & & & \\
\hline
\end{tabular}

Berdasarkan Tabel 6 diketahui bahwa responden nilai kandungan timbal dalam urin perokok aktif menggunakan $\mathrm{HNO}_{3}$ ditambahkan $\mathrm{H}_{2} \mathrm{SO}_{4}$ didapatkan persentase nilai recovery $46,48 \%$ dan nilai koefisian varian $50,58 \%$. Hasil uji akurasi untuk metode destruksi basah dengan menggunakan $\mathrm{HNO} 3$ mempunyai rata-rata recovery $71,8 \%$ sedangkan menggunakan $\mathrm{HNO} 3$ ditambahkan $\mathrm{H}_{2} \mathrm{SO}_{4}$ mempunyai rata-rata recovery $46,48 \%$. Hal ini menunjukkan metode destruksi ini memiliki nilai yang rendah dari nilai persentase recovery yang disarankan, yaitu pada rentang $100 \% \pm 15 \%$. Hal ini disebabkan oleh beberapa factor, yang pertama adanya ketidakpastian dalama kurasi baik dalam penggunaan alat maupun dalam pembacaan skala. Kedua faktor temperatur juga ikut berperan dalam kesalahan kalibrasi sehingga menyebabkan ketidakpastian baku.

\section{Uji Presisi Analisa Timbal dalam Urine Perokok Aktif.}

Koefisien variasi meningkat seiring dengan menurunnya konsentrasi analit. Pada kadar $1 \%$ atau lebih, standar deviasi relatif antara laboratorium adalah sekitar 2,5\%. Pada kadar satu per sejuta (ppm) RSDnya adalah $16 \%$, dan pada kadar part per bilion (ppb) adalah $32 \%$. Pada metode yang sangat kritis, secara umum diterima bahwa RSD dimana harus lebih dari $2 \%$. Kriteria seksama diberikan jika metode memberikan simpangan baku relatif atau koefisien variasi $2 \%$ atau kurang. Akan tetapi kriteria ini sangat fleksibel tergantung pada konsentrasi analit yang diuji, jumlah sampel, dan kondisi laboratorium. RSD $\leq 1 \%$ sangat teliti, $>1 \%$ dan $\leq 2 \%$ teliti, $<2 \%$ $\leq 5 \%$ ketelitian sedang, $>5 \%$ tidak teliti. 


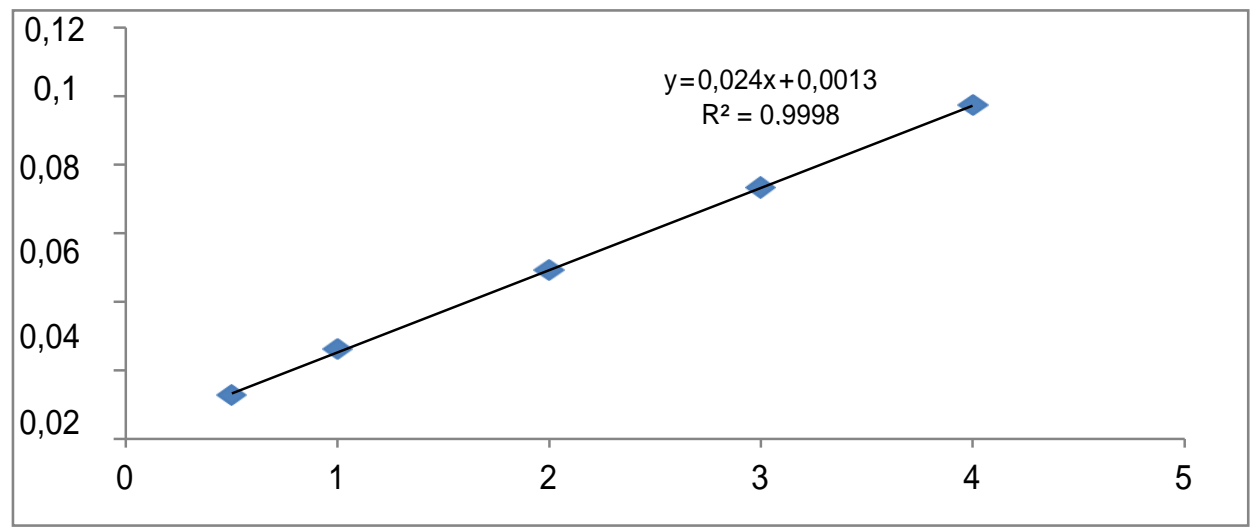

Gambar 1. Hasil Uji Presisi Pemeriksaan Pb dalam Sampel Urin perokok akif

Pada hasil perhitungan rumus didapatkan Nilai persentase RSD melalui metode destruksi pada $\mathrm{HNO}_{3}$ sebesar 28,80\%. Sedangkan pada $\mathrm{HNO}_{3}$ ditambahkan $\mathrm{H}_{2} \mathrm{SO}_{4} 50,58 \%$ nilai yang diperoleh di atas pada rentang yang disyaratkan yaitu $>5 \%$. Seluruh hasil metode yang telah dilakukan dalam penelitian ini menunjukkan hasil uji dari metode destruksi basah menggunakan $\mathrm{HNO}_{3}$ menunjukkan hasil yang belum teliti dan menggunakan $\mathrm{H}_{2} \mathrm{SO}_{4}$ juga belum dapat dikategorikan teliti. Sehingga dapat disampaikan bahwa destruksi metode ini belum dapat dipercaya atau belum valid untuk menganalisa $\mathrm{Pb}$ dalam urin dengan menggunakan AAS.

\section{Uji Linearitas Analisa Timbal dalam urin Pada Perokok Aktif}

Grafik linieritas pengukuran $\mathrm{Pb}$ Berdasarkan pengukuran sederet larutan standar, diperoleh nilai kolerasi (r) 0,999. Pada Gambar 1 dapat dilihat bahwa kurva kalibrasi standar tersebut mempunyai garis singgung yang linear, sehingga respon yang diberikan alat terhadap kosentrasi analit telah memenuhi syarat. Nilai yang diperoleh telah memenuhi syarat yang ditetapkan, dengan ketentuan $r<0,99$. Hasil tersebut menunjukkan alat yang digunakan mempunyai respon yang baik terhadap sampel. Linieritas adalah suatu koefisien korelasi antara kosentrasi larutan standar baku dengan absorban yang dihasilkan yang merupakan suatu garis lurus. Metode analisis juga menggambarkan kemampuan suatu alat untuk memperoleh hasil pengujian yang sebanding dengan kadar analitik alat dalam sampel uji pada rentang kosentrasi tertentu. Uji linieritas dilakukan dengan membuat kurva kalibrasi yang dapat menghasilkan persamaan garis regresi serta nilai koefisien determinasi.

\section{Uji Limit of Detection (LoD) dan Limit of Quantitation (LoQ) Analisa Timbal dalam Urin Perokok Aktif}

Parameter limit deteksi (LoD) instrumen menunjukkan kosentrasi terkecil yang dapat terbaca oleh instrumen. Apabila kosentrasi berada di bawah limit deteksi maka sinyal yang ditangkap alat adalah sepenuhnya baik. Kosentrasi analit yang berada pada limit deteksi sudah sepenuhnya dapat dipercaya karena akurasi yang dihasilkan tinggi. Dari larutan standar baku $\mathrm{Pb}$ diukur, dengan menggunakan $\mathrm{HNO}_{3}$ tambah $\mathrm{H}_{2} \mathrm{SO}_{4}$ dimana yang mendeteksi batas antara yang terukur dan menghasilkan kosentrasi terendah untuk $\mathrm{Pb}$ adalah 0,68\%. Sedangkan menggunakan $\mathrm{HNO}_{3}$ mendeteksi kosentrasi terendah adalah $0,77 \%$.

Sementara itu, limit kuantitas (LoQ) didefinisikan sebagai kosentrasi analit terendah dalam sampel yang dapat ditentukan dengan presisi dan akurasi yang dapat diterima pada kondisi operasional metode yang digunakan. LoQ merupakan suatu kompromi antara kosentrasi dengan presisi dan akurasi yang dipersyaratkan. jika presisi tinggi dipersyaratkan, maka kosentrasi LoQ lebih 
tinggi harus dilaporkan. Hasil $\mathrm{LoQ} \mathrm{HNO}_{3}$ ditambahkan $\mathrm{H}_{2} \mathrm{SO}_{4}$ didapatkan dari perhitungan Rumus adalah $22,6 \%$, dan nilai hasil LoQ pada $\mathrm{HNO}_{3}$ didapatkan 25,3\%.

\section{KESIMPULAN}

Berdasarkan hasil penelitian yang didapat:

1. Pada sampel kandungan $\mathrm{Pb}$ dari urin perokok aktif rata rata masih di bawah $\mathrm{NAB}$ yaitu sebesar $0,384 \mathrm{mg} / \mathrm{l}$ dengan $\mathrm{HNO}_{3}$, sedangkan dengan memakai larutan $\mathrm{HNO}_{3}$ ditambahkan $\mathrm{H}_{2} \mathrm{SO}_{4}$ yaitu sebesar 0,856 $\mathrm{mg} / \mathrm{l}$. Normal kadar $\mathrm{Pb}$ dalam urin sesuai dengan Kepmenkes NO.1406 tahun 2002 yaitu $<10 \mu \mathrm{g} / \mathrm{L}$ Urin.

2. Berdasarkan perolehan harga Presisi $\mathrm{HNO}_{3}$ yaitu $28,80 \%$, Sedangkan harga Presisi $\mathrm{H}_{2} \mathrm{SO}_{4}$ ditambahkan $\mathrm{HNO}_{3}$ yaitu 50,58\%. Pada validasi metode destruksi basah menggunakan $\mathrm{HNO}_{3}$ dan $\mathrm{HNO}_{3}$ ditambahkan $\mathrm{H}_{2} \mathrm{SO}_{4}$ analisa unsur $\mathrm{Pb}$ dengan kisaran kosentrasi tesebut belum bisa dikatakan teliti karena hasil yang didapat dari penelitian dengan ketentuan harga Presisi $>5$.

3. Berdasarkan perolehan harga Akurasi $\mathrm{HNO}_{3}$ yaitu sebesar 71,8\%, dan harga Akurasi pada $\mathrm{HNO}_{3}$ ditambahkan $\mathrm{H}_{2} \mathrm{SO}_{4}$ yaitu sebesar 46,48\%. Pada validasi metode destruksi basah menggunakan $\mathrm{HNO}_{3}$ dan $\mathrm{HNO}_{3}$ ditambahkan $\mathrm{H}_{2} \mathrm{SO}_{4}$ analisa unsur $\mathrm{Pb}$ dengan kisaran kosentrasi tersebut masih dibawah dan dapat dikatakan belum memenuhi persyaratan dengan ketentuan harga akurasi pada rentang $100 \% \pm 15 \%$.

\section{DAFTAR KEPUSTAKAAN}

Achadi, E. L. (2008). Gizi dan Kesehatan masyarakat. Jakarta: PT. Rajagrafindo Persada.

Al Anshori. (2005). Spektrofotometri Serapan Atom. Materi Ajar Kimia,.
Jakarta.

Amirudin R. (2009). No Title. Buku Ajar Ilmu Penayakit Dalam: Fisiologi Dan Biokimia Hati, V(Internet Publishing), 627.

Bjork, J., Albin, M., Mauritzson, N., Stromberg, U., Johansson, B., and Hagmar, L. (2000). Smooking and Myelodysplstic Syndromes (1th ed.; Lippincott Williams \& Wilkins., ed.). New York.

Handoy S.Y. (2008). Anatomi dan Fisiologi untuk Paramedis (2nd ed.). Jakarta: Gramedia Pustaka Utama.

Harmita, D. (2006). Analisis Fisiko Kimia.

John Adamson, A. W. (1990). Physical Chemistry Of Surface (5th ed.; John Wille \& Sons, ed.). Ner York.

Khopkar, S. (2008). Konsep Dasar Kimia Analitik. Jakarta: UI Press.

Lawrence, S. . (2003). Liver Chirrosis in: Lawrence M., Tierney Jr, Stephen J, McPhee, Maxine A Current medical Diagnosis and Treatment. ed 42. New York: McGrawHill.

Manahan, S. . (1992). Enviromental Chemistry.6th (Ed. Lewis, ed.). Publisher.USA.

Mayaserli, D. P., Renowati, R., \& Biomed, M. (2018). ANALISIS KADAR LOGAM TIMBAL (Pb) PADA RAMBUT KARYAWAN SPBU. Sainstek: Jurnal Sains Dan Teknologi, 9(1), 19. https://doi.org/10.31958/js.v9i1.606

Palar, H. (1994). Pencemaran dan toksikologi logam berat.

Sitepoe, M. (2000). Kekhususan Rokok Indonesia. (1st ed.). Jakarta: PT Grasindo. 